\title{
African Environmental Ethics
}

\author{
Joseph Nkang OGAR \\ Department of Philosophy, University of Calabar. Cross River State
}

\author{
Samuel Akpan BASSEY \\ Department of Philosophy, University of Calabar, Nigeria \\ samuelbassey15@yahoo.com
}

\begin{abstract}
For decades now, experts have studied and documented the severe environmental and land degradation across Africa. However, the nature of the problem has now been ratcheted up by mounting and undisputed scientific evidence demonstrating a clear causal link between tropical deforestation and global climate change. The external observers of the deteriorating African landscape continue to watch in alarm, sometimes heralding a concerted global response. The African environmental "crisis" that once was framed solely in the context of the direct effects of desertification, deforestation and land degradation on African ecosystems, economies and societies, is now in fact unhinged from the location of rapidly advancing desertification and deforestation to a much broader, world-wide crisis. There is now a rapid need for an effective environment ethic hinged on socio-cultural substance which recognize indigenous people, further shape their association with natural habitat. The thrust of this paper is to have a look at African environmental ethics.
\end{abstract}

KEYWORD: Africa, Environmental ethics, ecosystems

\section{Introduction}

The Western environmental movement is identified in history with new ways of thinking that emerged in literature, science and public discourse, bringing to awareness the environmentally destructive path on which her civilization had embarked in the name of industrialization and modernization. Environmental philosophy provided the justifications and rationale behind the western environmental awakening. This article asks and attempts to answer this questions with respect to Africa: To what extent has Western environmental ethic direct import into the African context and what is the value of philosophy that comes out of Africa itself - of an ethic from within? What, if any, are the dominant African environmental ethics and why have these philosophies failed to mobilize the African political machinery towards the protection of the African ecosystem? Is such an ethic sufficient to begin to address deforestation — one of Africa's (and the world's) most critical environmental issue?

J. Baird Callicott (1994) observed that finding some environmental ethic (or ethics) consonant with the African experience and ideas was a dire necessity, driven by the unique context-specific nature of the assault on the environment in Africa. Baird's concern about Africa begins with an observation that the continent has some unique and endemic environmental problems. But equally unique is the set of moral and cultural experiences shape and determine the relationship between man and nature. Perhaps the ethic with the potential to rescue Africa's environment lies in the richness of African cultures. The environmental ethics of Africa would therefore not come from Western philosophy. Neither would their root be extra-territorial. African environmental ethics would be embodied in the traditions of African people, a sort of ethics from within. 


\section{African Environment and Tropics}

While all life on our planet is affected by environmental problems, and few of the world's ecosystems have not been disturbed from their natural state of flux, Africans and their environment experience these impacts very directly. The relationship between the African people and their environment is much like the two sides of a coininextricably connected yet in constant opposition. The people, one side of the coin, live in close dependence on the service-value of natural resources. On the other side of the coin is the environment: the land, climate, water resources which are so intimately connected in a physical and metaphysical sense to the African people. This interdependence manifests itself in a love-hate relationship; love-because the land and the people are connected in a historical song-dance, meshed in the traditions that make the people "African" and identify the land as African soil; hate-because the intimacy of the relationship and connectedness of the African people, their economies, their politics, their religion, to their natural environment brings to the fore the inadequacies of the dominant partner, embroiling the couple in moral wars labeled "slash-and-burn," "soil erosion," "famine," and "deforestation."

Four types of environmental degradation are among the worst of Africa's environmental problems (Mathieu 1999).

(1) Desertification, the transformation of productive land to wasteland, is estimated at 36,000 square kilometers every year (Mathieu 1999). The factors creating conditions conducive to this rapid desertification are: localized population density pressure, the migration of many able rural workers to the cities, over-cultivation, overgrazing, and inadequate land/forestry management (Mathieu 1999).

(2) Deforestation in Africa is extreme, primarily driven by economic pressure to move onto additional farming land to sustain cash crop production (Mathieu 1999). The demise of Africa's forests is both externally and internally driven. The rise in wealth in parts of the world like China and India, and the continued need for food security in western countries are working together to raise commodity prices and increase pressure on agricultural lands across the developing world, who tend to be natural resource wealthy - especially in land resources. Internally, the direct use of forests for timber and for domestic energy uses accounts for a significant loss of Africa's forests. There have been remarkable efforts at reforestation, but reforestation is only replacing about $10 \%$ of the annual loss (Mathieu 1999). To put these numbers into perspective, it is estimated that in the 1980s alone, Africa lost $7 \%$ of its forests.

(3) Pollution of land, water and air in Africa can be blamed on a whole host of causes, but toxic dumping by Western multinational corporations, especially due to operations in African oil fields is most notable (Savaşan 2017).

(4) the disappearance of wildlife is unprecedented in Africa. Population pressures, poaching, and the tradition of separating wildlife from human populations have resulted in the loss of vast numbers of Africa's wildlife (Morris 2001). A stark picture is presented in the case of Kenya, where the elephant population dropped from 165,000 to 16,000 between 1970 and 1990 (Morris 2001).

Both deforestation and desertification, regardless of where in the world they occur, contribute significantly to global warming. When forests are cleared, carbon stored above and below ground in leaves, branches, stems and roots is released to the atmosphere. As a consequence, forest clearing, especially in the tropics, is a major source of $\mathrm{CO} 2$ to the atmosphere. One estimate shows that land use change, primarily deforestation, releases about $5.9 \mathrm{GtCO} 2$ (gigatons or billion metric tons of $\mathrm{CO} 2$ ) annually, about $17 \%$ of all annual anthropogenic GHG emissions. The Africa Summit report placed the lion's share of the blame for Africa's environmental issues on new technologies and population growth (Ahmed \& Hanson 2011). Technology has 
generated an increase in solid mineral mining and oil exploration, an increase in the number of plants and factories, and an overall upsurge in the application of manufacturing tools. Irresponsible industrialization, characterized by explosions, chemical and radioactive contamination, and other technological incidents increase the direct harms inflicted on the environment by Africa's technological advancement trajectory. The results include reduced quality and richness of terrestrial, freshwater, and marine environments, air and land pollution.

On the other hand, rapid population growth and its companion problems have placed the African natural environment in jeopardy. Globalization also places greater demands on land to produce cash crops for export, which facilitates economic growth but blazes the trail for environmental degradation (Ikegbu \& Bassey 2018). With an increasing global population, natural disasters are resulting in damage, loss of life and displacement of populations. Human-induced changes to the environment have reduced its capacity to absorb the impacts of change and to deliver the goods and services to satisfy human needs.

African economics suggest an unconsciously anthropocentric view of man's relationship to the natural environment. Ogungbemi (2008) observed that modern day Africa has benefitted from Western civilization and industrialization even as the West has in turn benefitted from the exploitation of Africa. However, he posited that, because of the desire to develop like Europe and the US, African governments (often in conjunction with international corporations) have engaged in mass destruction of ecosystems. The drive to develop has led to wholesale abandonment of traditional practices and values of forest land management as if development and modernization were incompatible with conservation of forest and protection of trees. But the economic trajectory of Africa is not evidence of wanton disconnection from environmental stewardship. With populations burgeoning, African governments are faced with the insurmountable burden of feeding the millions on disproportionately small budgets. As societies industrialize and achieve middle-class lifestyles, they tend to use more resources and produce more pollution, resulting in more environmental degradation. This economic reality has naturally forced a shift from subsistence farming to mechanization, often accompanied by the loss of traditional land management practices.

However, viewing African economic development with rose lenses terminates the analysis prematurely. Although it is true that population growth has forced the switch from traditional subsistence to the use of technology, African consumerism has contributed to the Western-like trajectory of development. Ogungbemi puts it more bluntly: “...[M]odern Africa does not want to eat and drink only what is produced locally; it has been infected with a desire for the Western lifestyle, and to cope with this modern lifestyle it has to import goods from industrialized nations" (Ogungbemi 2008). The increase in imports forces an increase in the domestic production of Africa's export goods: coffee, tea, cocoa, rubber, oil, mineral ore which can only be accomplished efficiently through technological advancement.

The development economics rationale of the environmental situation in Africa has been inadvertently christened by the United Nations Framework Convention for Climate Change (UNFCCC). The convention recognizes the need for African governments to develop their national economies by affirming that developing countries have a right to development, defined by the UNFCCC in Article 3(4) as "a right to. . .sustainable development" requiring each Party to "tak[e] intoaccount that economic development is essential for adopting measures to address climate change" (United Nations 1992). Further, Article 3(5)states that the Parties to the UNFCCC should cooperate to achieve "sustainable economic growth and development in all Parties" (United Nations 1992). A major concern for developing countries was that efforts to 
address climate change would overlook the fact that limiting the carbon emissions of developing countries would impede efforts to develop their economies. African governments do not perceive of an economic development trajectory that does not involve fossil-fuel driven technology and squarely bill the cost of development by alternative technologies on the West. All these signs point to a develop-or-die attitude, shrouded in a deeply anthropocentric man-nature relationship.

In fairness to the African development trajectory, an important and unanswered question is what is the alternative? Can a developing civilization avoid the environmental crises witnessed in the developed world by developing using renewable energy, for example? What would it cost? Or is it simply a matter of smarter use of the same technologies that have invaded our natural environment and destabilized its future? Is renewable energy not by default accessible only to the developed world because it requires high technology, research and development and capital investment? All these questions would need to be answered concretely before the anthropocentric African development trajectory can be regarded as a wanton march towards environmental apocalypse.

\section{Multiplicity of Factors Aggravated the State of the Environment}

In addition to the dominance of economic development on the African agenda, at least four other factors contribute to environmental degradation in Sub-Saharan Africa: (a) the subjugation of environmental interests during the colonial period and its continuing legacy; (b) the conundrum of predominately agrarian economies which locks people into a dependence on arable land and rain patterns; (c) abject poverty; and (d) totalitarian political structures that limit the African's access to democratic mechanisms to protect the environment.

Africa's current environmental problems cannot be unhinged from their historical context, particularly the impact of colonization on land and other natural resources. According to the Oxford Encyclopedia of African Thought, mining and cash crop farming were the two most significant environmental changes Africa experienced under colonization (Biodun and Irele 2010). Europeans restructured the way Africans traditionally farmed or otherwise used the land. Further, Africans were forced to overuse land as Europeans restricted them to areas with poor soil in the name of conservation and sport hunting. Colonialism also gave private companies a foothold in Africa, allowing for the growth of multinational companies who exploited natural resources such as diamonds, oil, forests, animals, gold and mono-cultural cash crops (Biodun and Irele 2010).

Most detrimental to the success of sustainability principles, the legacies of colonialism led to overdependence on single-drivers of government funds without any wide-scale diversification of the economy for the people. Sub-Saharan Africa is acutely vulnerable to threats to agricultural existence. Consequently, land is the backbone of Sub-Saharan economies. Agriculture contributes about 40 per cent of the regional gross domestic product (GDP) and provides livelihoods to about 60 per cent of the population (SAIIA 2005). Yet, arable land is not an abundant resource. Only 21 per cent of Africa's land is suitable for cultivation (SAIIA, 2005). Millions of hectares have been lost to soil degradation. Africa contains the world's largest expanse of drylands, covering roughly two billion hectares of the continent, or 65 per cent of Africa's total surface area (SAIIA 2005).

At the core of identifying and understanding the state of the Sub-Saharan environment is recognizing (political lenses off), that vulnerable groups lack the ability to adapt to, and cope with, change brought about by environment degradation. Adaptation requires resources in labor, technology, and capital. People in developing 
countries, particularly the least developed countries (LDCs) have less capacity to adapt to change and are more vulnerable to environmental threats and global climate change. Conversely, poverty remains the main cause and consequence of environmental degradation and resource depletion without significant improvement in the living conditions and livelihoods of the poor (SAIIA 2005). Further, poverty is an important cause of vulnerability to environmental threats. The poor tend to have much lower resource capacities, and therefore bear a disproportionate burden of the impact of disasters, conflict, drought, desertification and pollution.

The political structure of a society is a key determinant of the people's ability to control their natural environment. The vulnerability of Africans to environmental impacts is further exacerbated by such communities having little to no political power. Governing regimes control the political processes to thwart democracy, leaving the poor with no voice in the decisions that impact their natural resources (Oshita 2000). Participatory democracy is a vital prerequisite for the upgrading of the environment, enabling people to reclaim control and to hold authorities accountable for the communities they purport to serve. With these four unique factors muzzling the environmental agenda, Africa is ripe for a paradigm shift grounded in morality - that rational choice guided and constrained by something deeper than law.

\section{Articulating African Environmental Ethics}

Philosophical ethics is a process of stepping back to reflect on our decision making. African philosophers agree that environmental philosophy is meant to articulate the rights, duties and responsibilities of man to the environment and vice versa. Environmental philosophy exposes the environmental ethic of a group and helps to explain the choices structured societies make concerning the environment. The process of defining existing philosophies raises the kind of awareness that either confirms the shared ethic of society, or exposes its flaws in such a way that society rallies behind a change in course. According to H. Odera Oruka (2012)., philosophy is the base upon which all social practices are built. When we are forced to justify our lives, to justify our political system, to justify our legal system, to justify our marriage system, in the end the ultimate justification will have to be philosophy. The central question is whether western environmental ethics are pragmatic ways for Africans to relate to their environment, or whether universalism in environmental ethics is limited by the specific character of a civilization. The anthropocentric man, in whose company we have so far identified African development economics, sits at the other end of the spectrum, forlorn and shunned by the enlightened world of predominant western environmental ethics. Anthropocentrism is a kind of baseline against which Western environmental thinkers distinguish and measure the various theories. Each environmental ethic deviates from anthropocentrism to varying degrees based on the respective flaw it identifies. For example, eco-feminism contrasts itself from anthropocentrism by attacking the structure of domination that is common to man's treatment of woman and man's control over nature; animal rights theorists defend the animal's worth for moral consideration based on its capacity to feel pain - undermining a central rational behind elevating humans above other species in an anthropocentrically motivated desire to increase the comfort of man. In short, societies want to be viewed as superior, having evolved beyond anthropocentrism. In the world of environmental philosophy, to be anthropocentric is equal to being primitive, barbaric, torturing, rapists. The victim of the rampaging caveman is not just nature, she is sensing, alive, multifaceted, and pleading for a revolution that would free her.

So why identify a particularly "African" environmental ethic? After all, the dominant philosophies on the environment seem robust enough, spanning from the 
rudimentary anthropocentric views of man to the movement-like tenets of deep ecology. Moral philosophy is the systematic endeavor to understand moral concepts and justify moral principles and theories. Moral philosophy seeks to establish principles of right behavior that may serve as action guides for individuals and groups. However, moral philosophies are particular to their historic and cultural contexts, so while Western environmental philosophies served (and continue to serve) as vehicles towards establishing higher moral relationships between man and the natural world, such philosophies have limited direct application in other parts of the world. Environmental ethics are unique to the experiences of specific cultures and are ineffective when imported wholesale into civilizations foreign to the philosopher's history and culture. The articulation of an African environmental ethic, therefore, is crucial for two reasons: first, Africa's environment is in a qualitatively unique crisis, one that must be considered with exactitude to its context. Second, even with globalization and the creation of the "global village," Samuel Huntington's clash of civilizations thesis still holds in support of the notion that we are not "one world." An African environmental philosophy is necessary to define how Africans ought to live in relation to the environment - an African environmental ethic is the moral canvas upon which Africa itself may advance its own response to African ecological problems, and in turn address its role in deforestation and land degradation.

A search for articulations of African environmental philosophy can be frustrating if one is expecting robust formulations that represent a body of knowledge shining light into the moral reasoning of the African. Callicott (1994) describes the seeming absence of African environmental ethic as a paradox. According to John S. Mbiti (1979), the philosophical systems of the different African peoples have not been formulated, but some of the areas where these can be found are religion, proverbs, oral traditions, ethics and morals of the society concerned. While it complicates the process of articulating environmental ethics, this gap is not entirely insurmountable. Callicott (1994) noted that it is possible to study moral philosophy in the absence of the traditional sources of evidence, such as the writings of philosophers. Studying societal structures and values may also be instructive. Societal characteristics held in common across Africa may provide the clearest window into the African view of man's responsibility and obligations towards nature. This bottom-up view studies the primary themes of African society with the goal of gleaning environmental ethics from rudimentary practice. Two characteristics of "Africanhood" are fundamental to the inquiry: traditional African religion and culture (particularly the culture of communitarianism).

In the conclusion to his essay, African Biocommunitarianism, Callicott wrote of the San, the south-central African people more commonly known as "bushmen:"

"The ecological significance of [the San] rock paintings, of Dogon and Yoruba sculpture, of the African drum and the African dance are beyond the philosopher's power to state and illuminate (at least beyond this philosopher's power to do so). One sees, hears, and feels in these nonverbal modes of human expression an attunement of African peoples to Africa's timbres and rhythms. What potential have they for an African environmental ethic? How much of Africa's human responsiveness to the land and care for its creatures is implicit, habitual, lived, rather than explicitly codified? In the unspoken and unthought realm of human knowing, there may repose African resources for an indigenous environmental conscience that other researchers using very different methods many one day disclose" (Callicott 1994, 172).

While pointing to something deep, Callicott's observations provide little guidance as to which aspect of African culture this organic environmental ethic may be derived. How could he? Of the 54 countries of Africa, each contains multiple ethnicities, each 
ethnicity defined by a culture that is in many ways unique. Yet, the idea that culture illuminates an ethic concerning the African's relationship to her natural environment is not an abstraction when the role of religion in the African context is appreciated. In proposing an analysis of African philosophy, John S. Mbiti (1979) pointed to religion as a crucial marker of the general African ethic. Religion is indispensable to the articulation of a practical African environmental ethic because it deeply pervades and influences the African psyche. Mbiti wrote:

"Because religious traditions permeate all departments of life, there is no formal
distinction between the sacred and the secular, between the religious and non-
religious, between the spiritual and material areas of life. Wherever the African is,
there is his religion; he takes it to the fields where he is sowing seeds or harvesting
crops... if he is a politician, he takes it to the house of parliament" (Mbiti, 1979: 2).

The bottom-up view of African morality therefore centralizes the pervasiveness of religion in identifying a uniquely African environmental philosophy.

Yet, reducing African culture to its identification in religion does not immediately solve Calicott's paradox. Mbiti (1979) estimated that there are as many as 3,000 African tribes, each adhering to its own religion. It is therefore useful to focus on unifying themes in an attempt to glean even a surface appreciation of indigenous African religions. A resounding feature of traditional religions is that they are not practiced for their personal or individual benefit, but for their community significance. African traditional religion is shared by each member of that community and is the thing that defines the community and gives it its character. In fact, Mbiti gives the community notion of religion an even more fundamental position by claiming that in Africa, to be human is to belong to the whole community, and to do so involves participating in the beliefs, rituals, ceremonies and festivals of that community. This communitarianism in the practice of religion leaks into the common culture of African societies. Placide Tempels wrote in 1956:

The Bantu cannot conceive of...the human person as an independent being standing on his own. Every human person, every individual is as it were one link in a chain of vital forces: a living link both exercising and receiving influence, a link that establishes the bond with previous generations and with the forces that support his own existence. The individual is necessarily an individual adhering to the clan (Okafor, 1982: 87).

Despite the pervasiveness of religion in African life, the problem with incorporating religious practice and norms into the articulation of an environmental ethic is that there is no "there" in African religiosity. Acknowledging the common hybridization of Catholicism with the many different traditional African religions, Joseph Ratzinger, for example stated: "[O]ne must say that the longed-for theologies africaine or African theology is more a program than a reality at present" (Dieter 2018). Judeo-Christian and Islamic influence on environmental ethics is easier to identify because the immutable texts that form the pinnacle of such religions also provides the manuscript by which adherents practice. Religious text has a pervasive and powerful norm-generating effect on its adherents and those over which primary adherents exert influence. As a result of this force, environmental ethics have for decades been associated with the dominant religion of civilizations. African religion, on the other hand, is passed down from generation to generation by the speech and conduct of adherents. Yet, its power to generate concrete norms is nevertheless salient: it requires no conversion, just birth; it cannot be opted out of; and it is not objected to by the modern-day African "state" in the same way that Western religion is, at least formally, wholly excluded from the governance in developed nations. 
The centrality of traditional religion to the African psyche suggests that an African environmental ethic must be somehow rooted in religion. However as Part IV, infra demonstrates, emerging articulations of African environmental philosophy surprisingly do not always ascribe a primary role to religion in forming African morality.

\section{Practical African Environmental Ethics}

In contrast to the centennial of Western environmental philosophy, an African theory of environmental ethics was only advanced as recently as 1997. Segun Ogungbemi (2008), a Nigerian philosopher, examined the nature of the environmental crisis in Africa and provided some moral and practical suggestions. He identified three principal factors contributing to the African ecological crisis: (1) ignorance and poverty; (2) misuse of science and technology; and (3) political conflict, including international economic pressure. These factors themselves suggest that the root causes of environmental degradation in Africa differ in character and magnitude from those that may be identified in the west. Western environmental philosophy arose out of the need to curb environmental problems caused mainly by industrialization. Being on the frontiers of science, the West has not failed the environment out of a lack of knowledge. Instead, western environmental philosophies have thematically blamed the anthropocentric domination of nature driven by western capitalism. Ogungbemi's suggestion that the misuse of science and technology have contributed to the environmental problems in Africa support a notion that Africa is on the same historic trajectory as its Western counterparts, with the primary difference being that Africa now has the benefit of the West's unattractive environmental history to take lessons from (Ogungbemi 2008).

For Ogungbemi, Africans have departed in practice from who they are at the core. He states that in modern Africa, the way in which land has been exploited goes contrary to African traditional philosophy:

Modern usage of our land by our society does not reflect a similar degree of
awareness of the importance of forests and trees for the maintenance of
environmental values. The drive to develop has led to wholesale abandonment of
traditional practices... as if development and modernization were incompatible with
conservation of forest and protection of trees. The consequence of this has been a
break-down in environmental stability... (Ogungbemi 2008, 332).

Ogungbemi's notion of traditional philosophy is something he calls the ethics of care. The ethics of care derives from the African traditional relationship with nature where men and women recognize the importance of water, land and air management, particularly the traditional ethic of not taking more than you need from nature. According to Ogungbemi, this is a moral code to "keep a reasonable balance among the various resources constituting the ecosystem." (Ogungbemi 2008, 330). However, even Ogungbemi admits that the concept of an ethics of care is not unique to traditional Africa. Indeed, his formulation of an African environmental ethic seems to strongly point to some important external applications, even if it is not entirely universal. Yet, if Africans practiced the ethics of care, forests would not be disappearing. Neither would deserts be advancing at the rate at which they are. Recognizing this parallelism between African practice and values, Ogungbemi takes a giant leap from traditional ethics of care to a formulation he believes is more applicable to Africa's contemporary situation. His contemporary ethics of nature-relatedness is a reformulation of the ethics of care. Key to the ethics of nature-relatedness is that it completely divorces itself from religion. Nature-relatedness has three basic elements: reason, experience and the will. The claim of the ethic of nature-relatedness is that our natural resources do not need man for their existence and functions. It is an ethic that "leads human beings to seek to co-exist 
peacefully with nature and treat it with some reasonable concern for its worth, survival and sustainability" (Ogungbemi 2008, 332).

The second attempt at articulating an African environmental philosophy once again seeks to divorce environmental morality from purely religious foundations. Lawrence Ogbo Ugwuanyi $(2011,5)$, another Nigerian philosopher does not purport to have identified specific theories of the environment. Rather, he suggests a "fresh basis on which alternative theories of environment from the African worldview could be explored." $\mathrm{He}$ advances three iterations of African environmental ethics-secular environmental ethics (one from the bioethical principles of the African world and the second from African morality) and an environmental ethic derived from African traditional philosophy and religion. Ugwuanyi proposed a bioethically based theory, grounded in the African theory of life.
Africans have a deep reverential deference for life. Its beginning is elaborately celebrated in pregnancy, birth, naming and initiation ceremonies. Its growth and continuity is leashed in adulthood, and adolescence rites, family rites and communal festivities. Its end is buoyantly celebrated in death rites, and funeral rites (Ugwuanyi 2011, 6)

However, African personhood or individuality is inextricably linked to the community. One is only human because he is part of the kin network. From this observation of the relevance of measuring and locating human life in the context of other things, Ugwuanyi $(2011,6)$. then formulates an ethic that "ought" to be in Africa: "The environment in Africa ought not to be seen and understood as an economic item only, but where and why to locate the significance and relevance of life itself." The natural environment, under this derived ethic inherently possesses social, metaphysical and ancestral worth.

The second strand of Ugwuanyi's secular environmental ethics is derived from the African moral world (as contrasted with the first strand which is bioethical), in particular the claim that morality in Africa is grounded in a form of communitarianism. Communitarianism is a theory of shared identity and good-will. From communitarianism flows Africa's core values: co-operation, consensus, reconciliation, and commonality (Ugwuanyi 2011, 5). Based on this claim, Ugwuanyi declares that a relationship with the environment that generates discord or factions among humanity cannot be permitted by the African moral principle of communitarianism. The African concept of "other," as applied to the environment means that promoting environmental well-being leads to a greater shared identity and goodwill.

Most cognizant of the omnipresence of traditional African religion is Ugwuanyi's third formulation of an African environmental ethic derived from African traditional philosophy and religion. His basis for claiming that traditional philosophy and religion are a third source of environmental ethics is the observation that, for traditional Africans, religion is a complete way of life. African religion is not textually preserved-rather it is captured everywhere through myths, legends, songs, dance, painting, carving, adages, symbol, sculpture, language. Lending support to the notion of environmental communitarianism, the practice of traditional religion itself is communal. The individual is identified with the religion of his community. An important distinction made in identifying the ethics grounded in traditional African religion is that these traditions have no pioneer, saint, or central proponent:

Unlike other world religions, African traditional religion has no founder. Hence its origin is hardly taken as a subject of interest. It is believed to have evolved slowly through many centuries as people responded to the situation of their lives and reflected upon their experience. Some of the factors which have contributed to the development of his religion include the universal human longing for the infinite; 
the quest for origin and source of things; the problem of evil, suffering and natural disaster, etc. Man reflected on all these and in search for answer (sic) he discovered that there is a supernatural, superior and living being who is greater than (man) and who controls and maintains the universe (Ugwuanyi 2011,7).

In his essay Some African Reflections on Biomedical and Environmental Ethics, Godfrey B. Tangwa (2007), a Cameroonian philosopher and the third voice speaking down the sparse well of African environmental ethics, described the traditional African environmental ethic as eco-biocommunitarian, i.e. the metaphysical recognition and acceptance of interdependence and peaceful co-existence between earth, plants, animals and humans. According to Tangwa (2007), traditional Africans were more cautious in their treatment and attitude towards plants, animals and inanimate things and the various invisible forces in the world. This observation is best explained by Ogwuanyi's description of the traditional personification of natural forces and phenomena, in which he states that whatever (African) people believe to be the home of sacred spirits, that thing becomes sacred: hills, mountains, rocks, trees, thick forests. Foundational to Tangwa's eco-biocommunitarianism is the "slim and flexible line" that exists between "plants, animals, and inanimate things, between the sacred and the profane, matter and spirit, the communal and the individual" (Tangwa 2007, 387).

The theories proposed by Segun Ogungbemi and Godfrey Tangwa, as well as the ethical and moral foundations laid by Lawrence Ugwuanyi do not easily collapse into one simplified single rule but what is clear is that each of the theories speaks to something that is both traditional, "of old," or "prior to modernization" and absent in the western experience. The point is most vividly demonstrated by Tangwa's ecobiocommunitarianism, which encompasses the African bioethic (celebrations of the sacredness of all life), the African's whole existence in his religion and its practice (the blurry line between the matter and spirit), and African communitarianism (nature being a part of the collective reason, will and experience).

\section{Conclusion}

Even though the power of traditional religion and culture in Africa suggest an environmental ethic that is enlightened, home-grown and uniquely African, the practical effect of African development economics forces a Western-style anthropocentrism which cannot easily be substituted with the more enlightened rudimentary and traditional philosophies. The result is a dual morality: a uniquely African environmental ethic located in the religion and culture of Africans, with its potential to reverse the African environmental crisis subdued by the anthropocentric trajectory of development economics.

The following recommendations may be useful in narrowing the gap between what is and what ought to be in African environmentalism: First, environmental philosophy should become a priority in African environmental discourse. Theorizing in ways that bring to the surface the dangers of pursing economic development while philosophically stagnated in anthropocentrism is a threat to the future of the African environment. Second, the rift between what is and what ought to be may be successfully narrowed by riding the wave of nationalism that was renewed in the 1990s in Africa. African nationalism, in its most useful form, seeks to promote indigenous values by validating a return to cultural values and norms. Such a policy could potentially evoke the religious and cultural traditions that once defined the African human relationship to nature. Third, and most difficult given the current development trajectory, Africans as a group would need to adopt the principle behind the ethics of care (not taking more than one needs) by curbing consumption patterns. This process presents the enormous challenge of changing the very traditions that promote overpopulation. 
The ideal is for the continent to find a way to collapse African traditional environmental philosophy, particularly the seed formulations of Ugwuanyi, Ogungbemi and Tangwa, into practice. After all, as Godfrey Tangwa $(2007,387)$ wrote: "In the domain of morality, correct practice without theory is preferable to correct theory without practice." Harnessing the old morality, a seemingly gigantic featfor any civilization, is probably the only way that Africa can begin to reverse the demise of its natural landscape.

\section{References}

Ahmed, A., \& Hanson, K. T. 2011. 'The critical role of capacity building in achieving sustainable development in Africa." World Journal of Science, Technology and Sustainable Development, 8(2/3): 101-110. http://doi.org/10.1108/20425945201100007

Callicott, J. B. 1994. Earth's Insights: A Multicultural Survey of Ecological Ethics from the Mediterranean Basin to the Australian Outback. Philosophy East and West (Vol. 46). http://doi.org/10.1525/j.ctt1 pnbx7

Dieter, T. 2018. "Joseph Ratzinger." In The Oxford Handbook of Ecclesiology (pp. 449-465). http://doi.org/10.1093/oxfordhb/9780199645831.013.6

Ikegbu, E.A. \& Bassey. S. A. 2018. "Globalization from WHO and for Who: A Tour to Reformed Imperialism." Journal of Advances in Education and Philosophy 2(5): 367-373

Jeyifo, Biodun, Irele, Abiola. 2014. The Oxford Encyclopedia of African Thought. The Oxford Encyclopedia of African Thought. http://doi.org/10.1093/acref/9780195334739.001.0001

Mathieu, P. 1998. "Population, poverty and environment degradation in Africa." Natures Sciences Societes 6(3): 27-34. Retrieved from http://www.scopus.com/inward/record.url?eid=2-s2.00242519471\&partnerID=40\&md5=ed0b1d56c3431bce3b4154f9d8dfe $16 \mathrm{~b}$

Mbiti, J. S. 1970. "Christianity and Traditional Religions In Africa." International Review of Mission 59(236): 430-440. http://doi.org/10.1111/j.1758-6631.1970.tb00979.x

Morris, B. 2001. "Wildlife conservation in Malawi." Environment and History 7(3): 357-372. http://doi.org/10.3197/096734001129342513

Okafor, S. O. 1982. "Bantu Philosophy: Placide Tempels Revisited." Journal of Religion in Africa 13(2): 83-100. http://doi.org/10.1163/157006682X00078

Oruka, H. O. 2012. "Cultural Fundamentals in Philosophy." Philosophy and Theology 5(1): 19-37. http://doi.org/10.5840/philtheol19905113

Oshita O. Oshita. 2000. Ken Saro Wiwa And The Trajectory Of The Minority Predicament In Nigeria, In Before I Am Hanged: Ken Saro Wiwa-Literature, Politics And Dissent 37 (Onookome Okome, Ed.)

SAIIA. 2005. Working together: assessing public-private partnerships in Africa. Nepad Policy Focus Report (Vol. 2).

Savaşan, Z. 2017. "Pollution, Land.” In Encyclopedia of Big Data (pp. 1-4). http://doi.org/10.1007/9783-319-32001-4_168-1

Segun Ogungbemi, 2008. An African Perspective On The Environmental Crisis, Environmental Ethics: Readings In Theory And Application 332 (Louis Pojman \& Paul Pojman, Eds).

Tangwa, G. B. 2007. "Some African Reflections on Biomedical and Environmental Ethics." In $A$ Companion to African Philosophy (pp. 387-395). http://doi.org/10.1002/9780470997154.ch31

Ugwuanyi, L. O. 2011. "Advancing environmental ethics through the African world-view." Mediterranean Journal of Social Sciences 2(4): 107-114.

United Nations. 1992. UNFCCC. Fccc/Informal/ 84, 1(3): 270-277. http://doi.org/10.1111/j.14679388.1992.tb00046.x. 